\title{
Experimental Investigation of the Confined Behavior of Dry and Wet High-Strength Concrete: Quasi Static Versus Dynamic Loading
}

\author{
E. Piotrowska ${ }^{1} \cdot$ P. Forquin ${ }^{1}$
}

Received: 28 January 2015/Accepted: 9 April 2015/Published online: 12 May 2015

(C) Society for Experimental Mechanics, Inc 2015

\begin{abstract}
This paper presents an experimental investigation of the behavior of high-strength concrete $\left(f_{c 28}=80\right.$ MPa) under very high pressure and quasi-static and dynamic loadings. Concrete specimen is inserted in an elastic, high-strength steel ring and subjected to an axial compression. In order to evaluate the confining pressure acting on concrete the ring is instrumented with multiple hoop strain gauges glued on its outer lateral surface. Dry and wet specimens are tested in both static and dynamic loadings in order to assess the influence of the free water content and the strain rate. Dynamic test are performed with a large diameter $(80 \mathrm{~mm})$ split Hopkinson pressure bar facility, adapted to test samples of large size (required for testing concrete material) at high stress levels. A strong effect of the free water content and the strain rate is observed in both deviatoric and volumetric behaviors of high-strength concrete. Both, the shear strength and volumetric stiffness increase with the increase of loading rate. One the other hand, free water has a beneficial effect on the volumetric stiffness and a strong negative influence on the deviatoric strength of high-strength concrete. The behavior of highstrength concrete was also compared to that of an ordinary concrete $\left(f_{c 28}=30 \mathrm{MPa}\right)$, tested in a similar experimental campaign. In both static and dynamic conditions, dry specimens of the two concretes reach approximately the same deviatoric stress level. However, when the specimens are saturated with free water, high-strength concrete exhibits a deviatoric strength much greater than ordinary concrete.
\end{abstract}

\footnotetext{
P. Forquin

pascal.forquin@3sr-grenoble.fr

1 UJF-Grenoble 1, Grenoble-INP, CNRS UMR 5521, 3SR Lab, 38041 Grenoble, France
}

Keywords High-strength concrete $\cdot$ Saturation ratio · Strain rate effect - Split Hopkinson pressure bar

\section{Introduction}

The complex concrete structures such as nuclear power plants, high-rise buildings, dams, tanks of dangerous materials, are nowadays exposed to various man-made and technological hazards (ballistic impact, blasting, plane crash, etc.). Thus, the behavior of concrete under highintensity stress states needs to be investigated in order to ensure the safety of military and civil constructions. This article focuses specifically on the stress states corresponding to the penetration of a rigid projectile into the structural core of a concrete target. In this loading phase a confinement is generated by a concrete material around the tunnel region within the target volume [25].

Two classical loading paths: triaxial compression and oedometric compression, has been previously applied to study the confined compressive behavior of concrete. In triaxial compression test a cylindrical specimen is first loaded hydrostatically up to a desired pressure and then compressed in the axial direction while keeping the lateral pressure constant. Different authors revealed the increase of concrete strength and ductility with the confinement [17, $18,22]$. A large experimental campaign was performed to characterize the triaxial behavior of an ordinary concrete, named R30A7 $\left(f_{c}=30 \mathrm{MPa}\right)[10,16]$. This concrete was tested at different saturation ratios [21]. Its initial mix composition was also modified to study the influence of cement paste volume and coarse aggregate size [19] and the effect of coarse aggregate shape and nature [15] on the concrete behavior. 
The second stress path allowing to measure the concrete strength at different levels of pressure and characterize the compaction of concrete is quasi-oedometric compression test. A concrete specimen is enclosed in a confining vessel and subjected to axial compression that generates both axial and radial stresses in the specimen. Different experimental devices were proposed for static quasi-oedometric compression test $[3-5,10]$. This loading path was also successfully applied in dynamic loading conditions [7].

A split Hopkinson pressure bar method previously developped to characterize the dynamic behavior of microconcrete MB50 [6, 8], a material attractive to be tested using relatively small specimens due to the max. aggregate size of $2 \mathrm{~mm}$, is adapted here to test a high-strength concrete made with aggregates of diameter up to $8 \mathrm{~mm}$. The specimen size was increased compared to the previous studies in order to be representative of the material regarding the aggregate size.

Most of the sensitive concrete structures are constructed with concrete characterized by a low water/cement ratio and high uniaxial strength. However, it was shown by $\mathrm{Vu}$ [20], that the uniaxial compressive strength of concrete is not a good indicator of its behavior at high confinement and yet, this is a loading type undertaken by concrete subjected to an impact. The present article is addressed to quasioedometric compression tests performed on high-strength concrete in both static and dynamic conditions. Regarding the fact that the core of massive concrete structure may remain wet during most of its lifetime due to a very slow drying process, both dry and saturated concrete specimens are tested.

The following section will briefly introduce basic characteristics of the concrete mix. Section 3 will provide a description of the quasi-oedometric compression test together with a recorded data processing method. The results of static experiments will be given in Sect. 4. A comparison of the high-strength concrete behavior with the behavior of an ordinary concrete characterized by the same volume ratio and size distribution of coarse aggregates will be drawn. Subsequently, the split Hopkinson pressure bar facility and dynamic tests results will be presented in Sect. 5 . Section 6 will summarize the study and provide the final conclusion.

\section{Concrete Formulation}

The concrete mix was previously designed to investigate the influence of the cement matrix porosity on the triaxial behavior of concrete [24]. For this purpose the composition of the cement matrix of previously tested ordinary concrete (R30A7), which will be simply denoted OC in the following, was modified in order to reduce the capillary porosity. The resulting mix is characterized by lower water to cement ratio (0.3 instead of 0.64$)$ and the presence of silica fumes. Following the method proposed by Sherbrooke University [1] the quantity of sand in the highstrength concrete was slightly reduced compared to the ordinary concrete. Both concretes are characterized by the same coarse aggregate volume and size distribution. Concrete mix compositions are presented in Table 1.

After pouring, the large concrete blocks were conserved for 1 month in water saturated with lime, then machined and dried in the oven at $50{ }^{\circ} \mathrm{C}$. The concrete is considered dry when the daily variation of mass does not exceed $0.1 \%$. Saturated specimens where never dried; after the machining process performed under water, they were conserved again in water until the time of preparation for testing.

\section{Quasi-Oedometric Compression Test Description}

Concrete specimen is a cylinder, $40.2 \mathrm{~mm}$ in diameter and $50 \mathrm{~mm}$ long. Such a specimen size allows testing concrete at high stress levels taking into account the size of SHPB device used in the present study ( $80 \mathrm{~mm}$ in diameter).

The specimen length to diameter ratio is a result of a compromise. A shorter specimen insures a better homogeneity of mechanical fields within the specimen under dynamic loading. On the other hand, the specimen must be large enough according to the maximum aggregate size ( 8 $\mathrm{mm})$ to ensure a good representation of the concrete material.

The specimen is tested within a high-strength steel ring characterized by an elastic limit of about $1800 \mathrm{MPa}$. It is compressed using two high-strength steel, cylindrical plugs. A series of numerical simulations were performed using a finite element commercial code Abaqus in order to set the dimensions of the confining ring (see Table 2). The

Table 1 Composition and basic properties of ordinary concrete (OC) and high-strength concrete (HSC)

\begin{tabular}{lll}
\hline Concrete & OC & HSC \\
\hline Siliceous gravel $D 0.5 / 8 \mathrm{~mm}\left(\mathrm{~kg} / \mathrm{m}^{3}\right)$ & 1008 & 1008 \\
Sand $D_{\max } 1.8 \mathrm{~mm}\left(\mathrm{~kg} / \mathrm{m}^{3}\right)$ & 838 & 795.4 \\
Cement CEM I $52.5 \mathrm{~N} \mathrm{PM}$ ES CP2 (Vicat) $\left(\mathrm{kg} / \mathrm{m}^{3}\right)$ & 263 & 420 \\
Silica fumes $\left(\mathrm{kg} / \mathrm{m}^{3}\right)$ & - & 46.7 \\
Superplastifiant $\left(\mathrm{kg} / \mathrm{m}^{3}\right)$ & - & 4.7 \\
Water $\left(\mathrm{kg} / \mathrm{m}^{3}\right)$ & 169 & 140 \\
Density $\left(\mathrm{kg} / \mathrm{m}^{3}\right)$ & 2278 & 2414.8 \\
Compressive strength $f_{c 28}(\mathrm{MPa})$ & 30 & 80 \\
Porosity accesible to water $v(\%)$ & 11.8 & 8.8 \\
\hline
\end{tabular}


Table 2 Dimensions of the confining ring and compressive plugs

\begin{tabular}{ll}
\hline Ring dimensions & \\
\hline$D_{\text {ext }}(\mathrm{mm})$ & 80 \\
$D_{\text {int }}(\mathrm{mm})$ & 40.5 \\
$L(\mathrm{~mm})$ & 60 \\
\hline Compressive plugs dimensions & \\
\hline$D(\mathrm{~mm})$ & 40.1 \\
$L(\mathrm{~mm})$ & 30 \\
\hline
\end{tabular}

goal is to allow accurate strain gauge measurements and prevent the ring from any plastic deformation. The internal diameter equals to $40.50 \mathrm{~mm}$, to ensure a very small gap between the specimen and the ring. The gap is filled in with a bi-components epoxy resin named Chrysor ${ }^{\circledR}$ C6120, while setting up the specimen. The illustration of the sample preparation procedure, allowing a very good alignment of the specimen and steel elements, can be found in [8].

The confining ring is instrumented with four transverse gauges, which are glued on its outer surface. The two gauges located in the half length of the ring are used to evaluate the radial stress and strain within the specimen. Two additional gauges, opposite located at a distance from the ring edges of $1 / 8$ of the ring length, allow evaluating the barreling of the ring.

\section{Processing of the Ring Gauges Signals}

The records of strain gauges located on the outer face of the confinement ring are used to calculate the radial stress and strain levels within the concrete specimen. The processing technique has already been described in $[5,7]$.

In order to evaluate the elastic modulus of the ring, compression tests in the direction perpendicular to the ring's axis were performed by means of a small laboratory press on two rings, each instrumented with the four strain gauges. Comparison of this experimental data with finite element numerical simulations provided the Young's modulus equal to $198 \pm 7 \mathrm{GPa}$. Then, a series of finite element numerical simulations of the elastic ring (Young's modululs: $198 \mathrm{GPa}$, Poisson's ratio: 0.29) subjected to a uniform internal pressure was performed, in order to establish relations between the internal pressure and the external hoop strains. The internal pressure can be evaluated, taking into account the axial deformation of the specimen during the test, according to [8]:

$\sigma_{r r}^{(i n t)}=P_{\sigma}(h) \varepsilon_{\theta \theta}^{(z=0)}$

where $P_{\sigma}(h)$ is a polynomial function of degree 2, which coefficients has been identified for the considered cell from numerical simulations for a range of the specimen height $h$ from 42 to $50 \mathrm{~mm}$. In the same way the internal hoop strains are evaluated: $\varepsilon_{\theta \theta}^{(i n t, z=0)}, \varepsilon_{\theta \theta}^{(i n t, z=h / 2)}, \varepsilon_{\theta \theta}^{(i n t, z=-h / 2)}$. The average radial strain along the specimen $\bar{\varepsilon}_{\theta \theta}$ may be computed knowing the outer hoop strains measured on the ring and the axial strain of the specimen [8]:

$\bar{\varepsilon}_{r r}=F\left(\varepsilon_{\theta \theta}^{(i n t, z=0)}, \varepsilon_{\theta \theta}^{(i n t, z=h / 2)}, \varepsilon_{\theta \theta}^{(z=-h / 2)}, \varepsilon_{z z}\right)$

The function $F$ takes into account the barelling deformation of the ring. Once the radial strain of the specimen is known, the average axial stress may be computed:

$\sigma_{z z}=\frac{F_{z}}{A_{0}\left(1+\bar{\varepsilon}_{r r}\right)^{2}}$

where $A_{0}$ is the initial specimen's section area and $F_{z}$ is the axial force applied to the specimen, obtained either from a force sensor located in the press (static tests) or from split Hopkinson pressure bar analysis (dynamic tests).

\section{Static Tests}

\section{Experimental Method}

Static tests were performed by means of a very high-capacity hydraulic press, named GIGA, able to reach stress levels in the concrete specimen of order of $1 \mathrm{GPa}$. The specimen fixed in a steel ring is placed in the press and subjected to the axial compression. The axial force is generated from a $13 \mathrm{MN}$ jack. An axial displacement sensor located in the press is used to control the axial jack displacement. The specimen is loaded with a displacement rate of about $0.1 \mathrm{~mm} / \mathrm{s}$. The deviatoric stress applied to the specimen is provided by a force sensor. The axial strain measurements are carried out by an LVDT sensor which outputs the length variation of the specimen.

\section{Results of Static Quasi-Oedometric Compression Tests Performed on the High-Strength Concrete}

This section presents the results of static tests performed on the high-strength concrete in both dry and saturated states. The specimen set-up inside the cell prevents from water loss and provides undrained testing conditions.

In order to check the accuracy of the results, each test was performed twice. The average strain rate was of order of $1 \mathrm{e}-3 / \mathrm{s}$. Figure 1a plots the volumetric responses of dry and wet specimens. Their deviatoric behaviors are displayed in Fig. 1b. Very good reproducibility of the results is obtained for dry concrete specimens. A slight variation in deviatoric strength of saturated samples is observed.

The presence of free water and thus high pore water pressure developing in the material in the compaction 


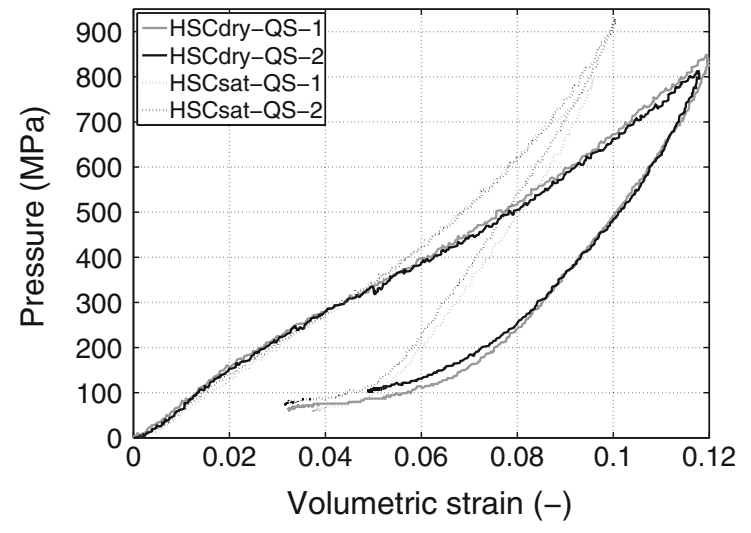

(a)

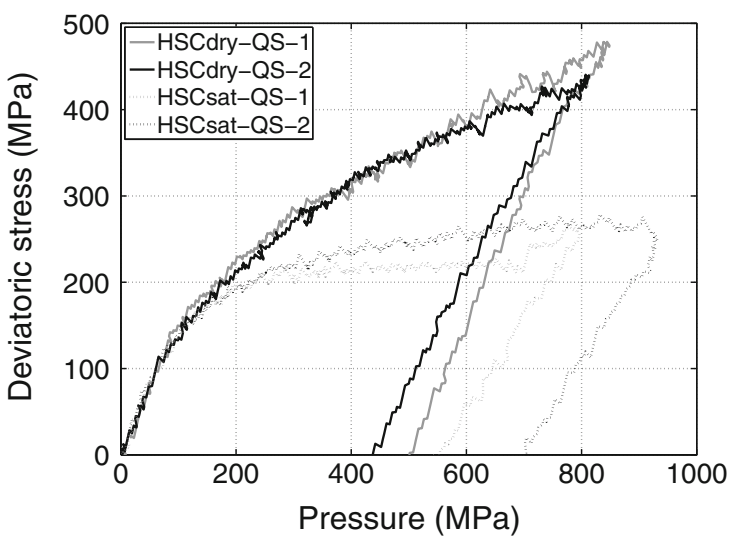

(b)

Fig. 1 Behavior of the high-strength concrete under static quasi-oedometric compression: dry and saturated specimens

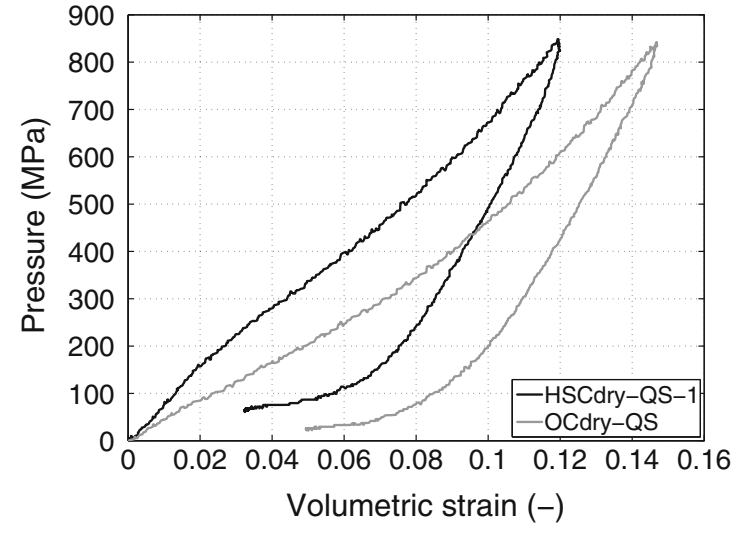

(a)

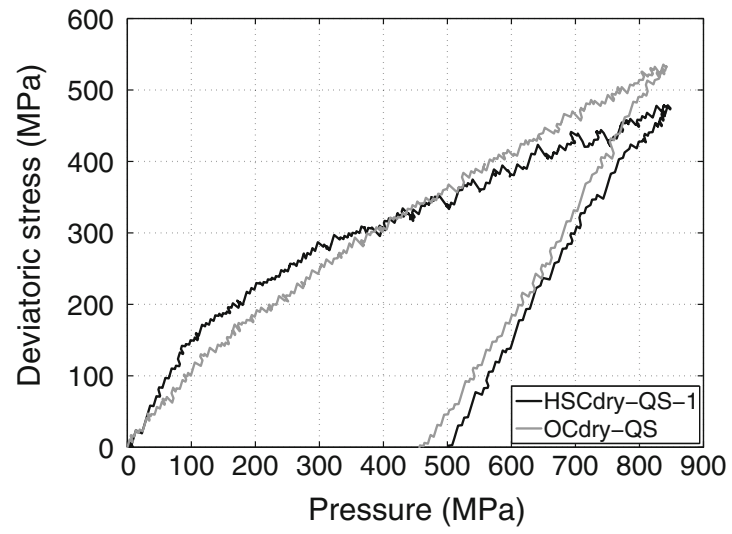

(b)

Fig. 2 Comparison of the behaviors of high-strength concrete HSC and ordinary concrete OC under static quasi-oedometric compression: dry specimens

process, is supposed to limit the concrete deviatoric strength and increase its volumetric stiffness. Such a behavior was already observed for an ordinary concrete, characterized by the uniaxial strength of $40 \mathrm{MPa}$, tested under triaxial compression at high levels of confining pressures [21]. The behavior of this ordinary concrete under quasi-oedometric compression will be introduced in the following section and compared to that of high-strength concrete.

\section{Comparison with the Behavior of the Ordinary Concrete}

The high-strength concrete is characterized by a low porosity compared to the ordinary concrete. The porosity accessible to water measured on the high-strength concrete equals $8.8 \%$ while that of ordinary concrete is $11.8 \%$. This difference produces different compaction curves for the two concretes (see Fig. 2a). The incremental volumetric stiffness is higher for the high-strength concrete. However, around $800 \mathrm{MPa}$ of the mean stress, the two concretes shows a similar volumetric stiffness, which may be explained by the important level of the cement matrix damage in the two concretes. Both concrete specimens undergo high plastic deformations coming from the porosity collapse and strong material compaction. The deviatoric strength difference between the two concretes are plotted in Fig. 2b. This difference varies with the level of the mean pressure. At low pressure levels the shear strength is higher for the high-strength concrete. However, at about $200 \mathrm{MPa}$ of the mean stress, a little stiffness reduction is observed for the high-strength concrete while the strength of the ordinary concrete increases almost linearly. At the end of the loading step, the stress level in the high-strength concrete is slightly lower than in the ordinary concrete. One may assume that due to lower porosity of the high-strength concrete water could have remain in its micro-structure 
during the drying process resulting in a slight increase of the pore pressure under high confinement and a lower shear strength. However, additional tests with pore pressure measurements should be conducted to validate this assumption.

Figure 3 compares the behaviors of the high-strength concrete and the ordinary concrete saturated with water. Certainly due to its lower porosity, high-strength concrete shows a stiffer volumetric behavior than ordinary concrete. Deviatoric strength of the wet high-strength concrete strongly exceeds that of ordinary concrete, contrarily to the behavior of dry specimens (Fig. 2b) which reach approximately the same deviatoric stress level. The strength of high-strength concrete in a fully saturated state is divided by approximately 2 compared to dry concrete. For the ordinary concrete, which shows a very poor strength when saturated, this ratio exceeds 7 . The porosity of concrete has thus an important effect on the shear strength when the concrete sample is wet.

Figure 4 presents the two concrete specimens after the test. In both concretes horizontal macroscopic cracks are observed. However, practically all aggregates are broken along the crack surface in the high-strength concrete while some aggregates are debonded in the ordinary concrete.

\section{Dynamic Tests}

\section{Experimental Method: Split Hopkinson Pressure Bar}

Dynamic quasi-oedometric compression experiments were performed with a large split Hopkinson pressure bar facility, a testing technique pioneered by Kolsky [13]. The SHPB system employed in this work and the data processing method are detailed in [7]. The experimental set up

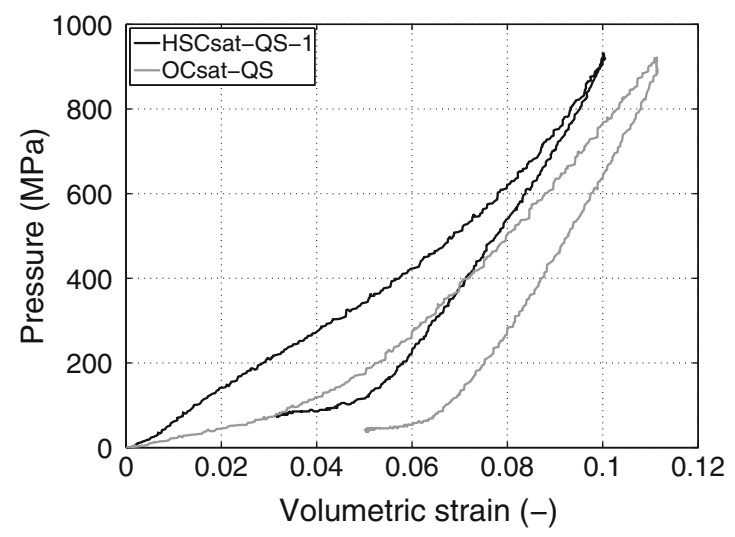

(a) consists in a striker, an input bar and an output bar, all made of steel bars with a diameter of $80 \mathrm{~mm}$. The striker, the input bar and the output bar are 2.2, 6 and $4 \mathrm{~m}$ long, respectively. The elastic limit of the steel elements is 1200 MPa.

When striker hits the free end of the input bar, a compressive longitudinal incident wave is created in the input bar. Once the incident wave reaches the interface between the specimen and the bar, a reflected pulse in the input bar and a transmitted pulse in the output bar are developed. These three basic waves, recorded by the strain gauges glued on the input and the output bars (see Fig. 5), are used to calculate forces and velocities at the specimen faces. Since the concrete specimen is located between the two compression plugs, and not directly between the input and output bars, this calculation is based on the analysis of the wave propagation in a bar with non-constant acoustic impedance $[2,11,23]$, taking into account the impedance change between the bar and the plug.
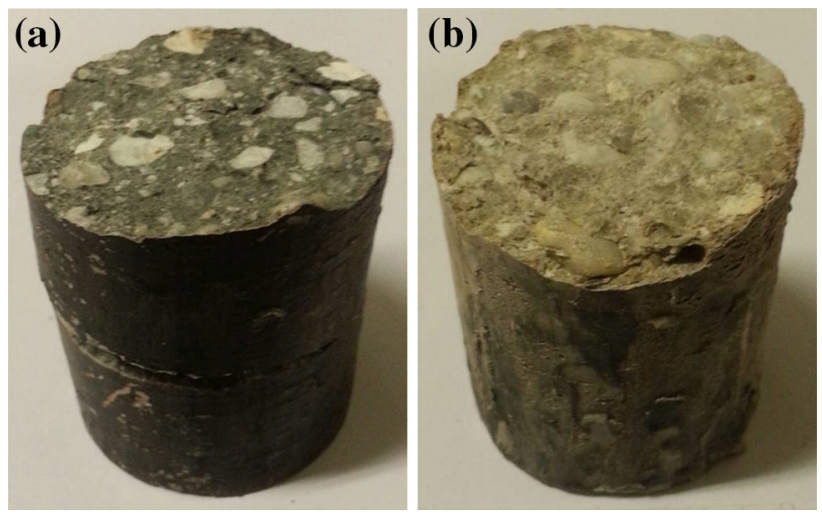

Fig. 4 Images of wet concrete specimens tested in static quasioedometric compression: a high-strength concrete, b ordinary concrete

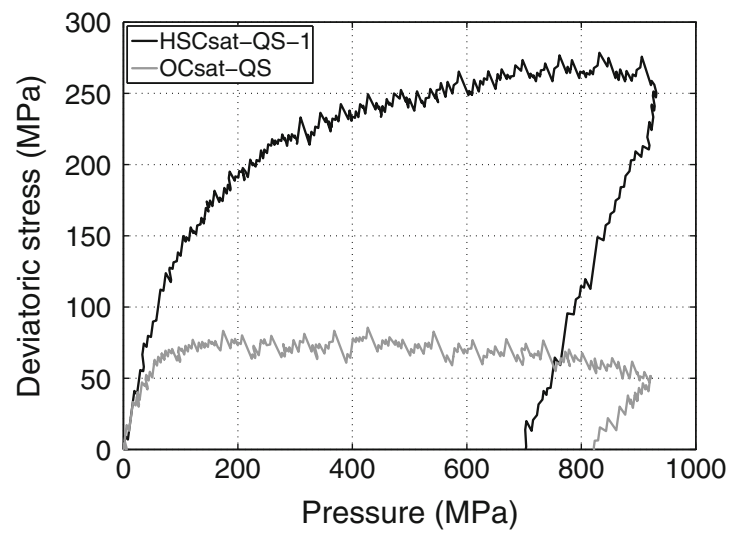

(b)

Fig. 3 Comparison of the behaviors of high-strength concrete HSC and ordinary concrete OC under static quasi-oedometric compression: saturated specimens 
In order to increase the rising time of the loading force and so to ensure the mechanical balance of the specimen in dynamic experiments a so-called pulse shaping technique is used [9, 14]. The method consist in placing a plasticallydeformable thin disk on the impact end of the incident bar. The profile of the incident bar can be controlled by the pulse shaper material and dimensions. A new pulse shaping technique for large-diameter SHPB using annual copper disk was recently developed and validated under uniaxial loading conditions [12]. In the present study a thin disk of lead (approx. $20 \mathrm{~mm}$ in diameter and $1 \mathrm{~mm}$ in thickness) was used to provide a slight increase of the rise time.

\section{Results of Dynamic Quasi-Oedometric Compression Tests Performed on High-Strength Concrete}

The results of dynamic quasi-oedometric compression tests performed on the high-strength concrete are discussed in the present section. Table 3 provides the average strain rate values for performed tests, including the experiments performed on the ordinary concrete that will be presented in

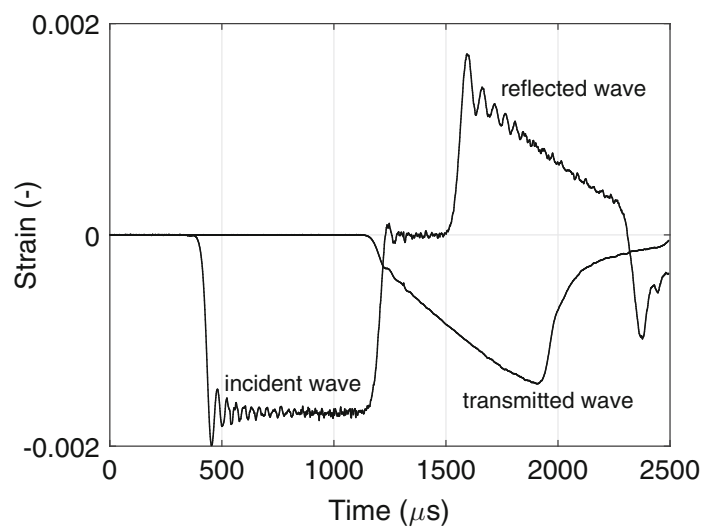

Fig. 5 Basic waves recorded in a dynamic test (striker speed: $17 \mathrm{~m} / \mathrm{s}$ )

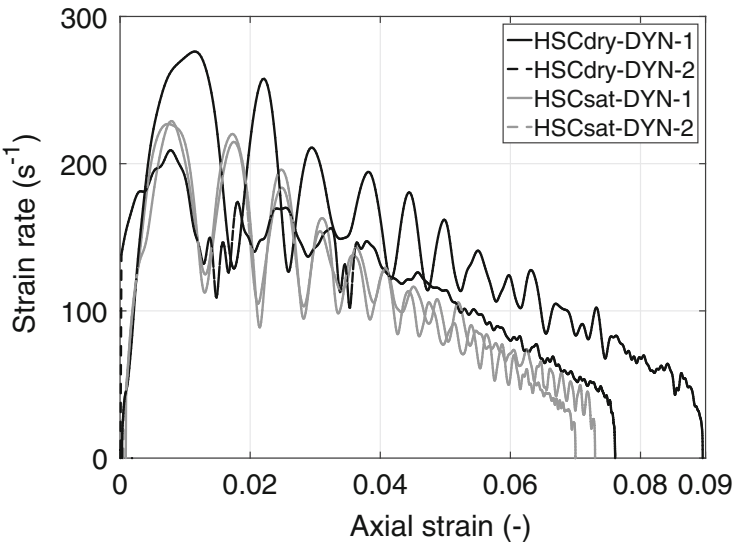

(a) the following section. The evolution of strain-rate in each dynamic test with the axial strain is presented in Fig. 6. The average strain rates are of order of $10^{2} / \mathrm{s}$. Due to a significant strain hardening resulting from the hydrostatic (pressure-volumetric strain) response of both concretes, the strain rate is decreasing during the test. However this drop seems not really significant as dynamic response is compared with experiments performed in quasi-static loading conditions (strain rate of order of $10^{-3} / \mathrm{s}$ ). Due to the very high pressures developed in wet concrete under confinement, the striker velocity was lower in tests performed on saturated specimens resulting in lower strain rates.

Output and input forces recorded in tests on highstrength concrete and ordinary concrete are plotted in Fig. 7. Balance of input and output forces is ensured by a short round-trip time in the specimen (about $50 \mu \mathrm{s}$ ) compared to the loading time (about $800 \mu \mathrm{s}$ ).

Figure 8 displays the results of dynamic tests performed on dry and saturated specimens of high-strength concrete. Regardless of strong oscillations coming from the noise of the gauges on the ring observed in tests on dry specimens, very good reproducibility of the results is obtained. The volumetric behavior of the high-strength concrete under dynamic loading seems to be almost independent of the

Table 3 Summary of dynamic quasi-oedometric compression tests

\begin{tabular}{ll}
\hline Test reference & Mean strain rate $(1 / \mathrm{s})$ \\
\hline HSCdry-DYN-1 & 111 \\
HSCdry-DYN-2 & 101 \\
HSCsat-DYN-1 & 93 \\
HSCsat-DYN-2 & 95 \\
OCdry-DYN & 151 \\
OCsat-DYN & 123 \\
\hline
\end{tabular}

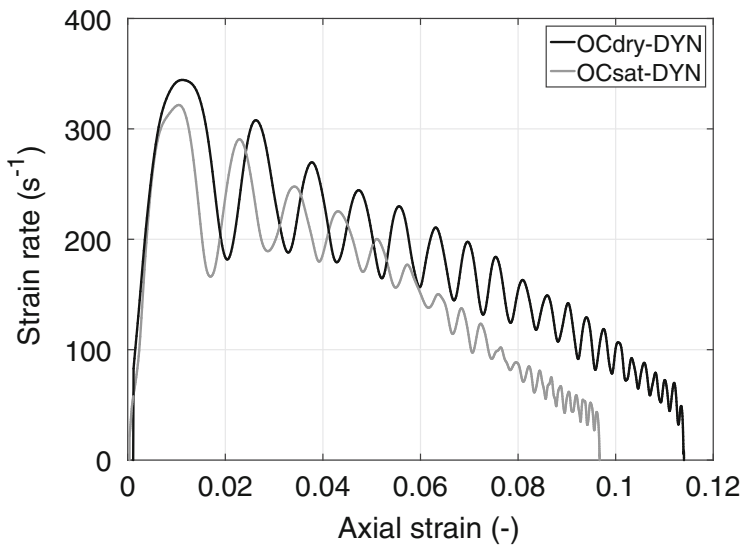

(b)

Fig. 6 Change of strain rate as a function of axial strain in dynamic tests: a high-strength concrete, $\mathbf{b}$ ordinary concrete 


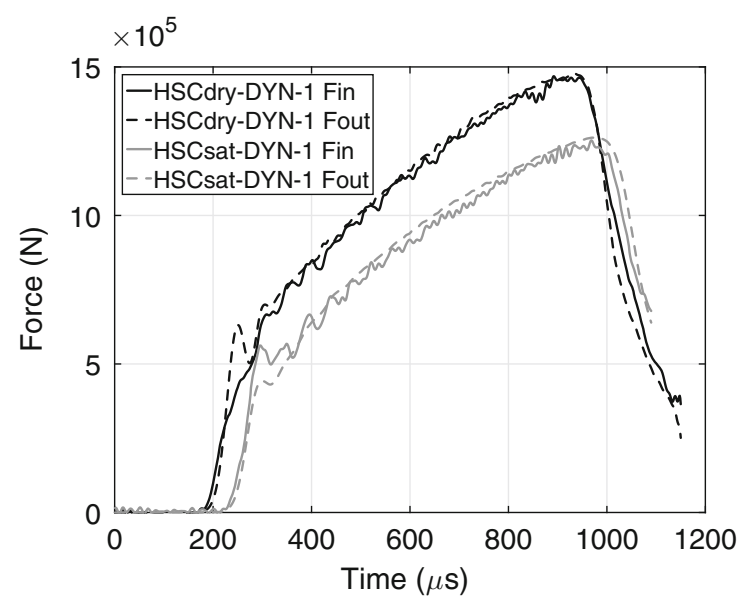

(a)

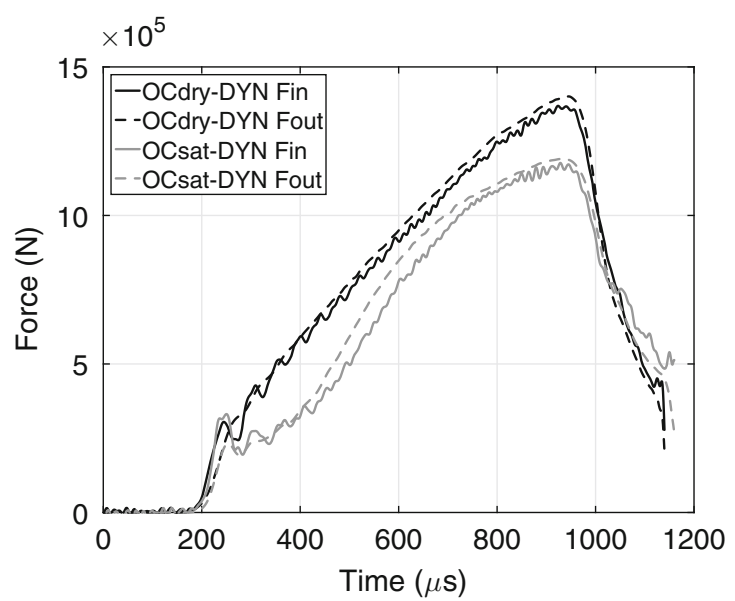

(b)

Fig. 7 Comparison of input and output forces in the specimen: a high-strength concrete, $\mathbf{b}$ ordinary concrete

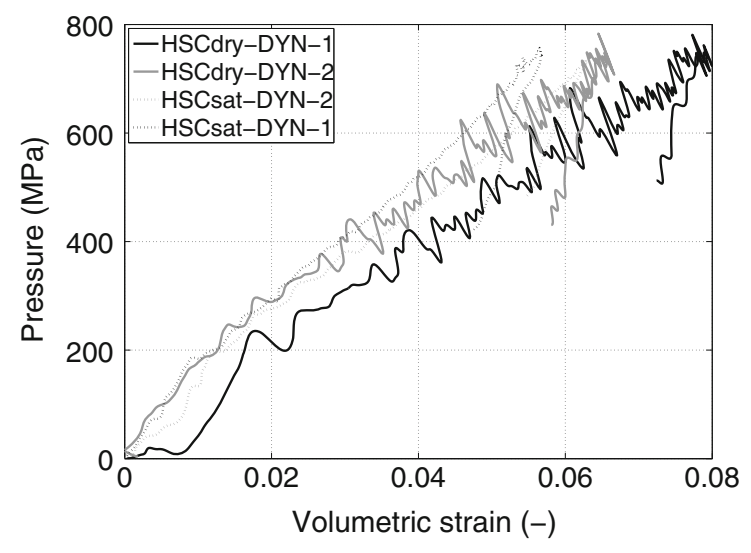

(a)

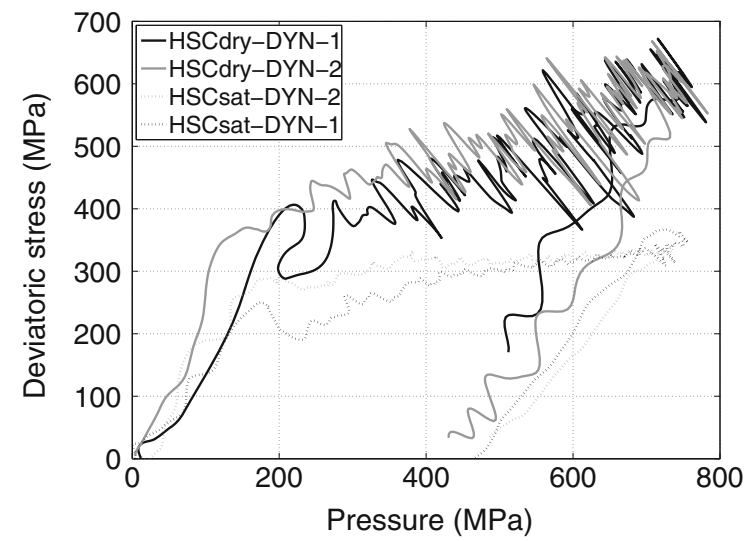

(b)

Fig. 8 Behavior of the high-strength concrete under dynamic quasi-oedometric compression: dry and saturated specimens

water content. Similar volumetric stiffness is observed for both dry and saturated samples. However, the presence of free water affects the deviatoric stress in concrete. As it has been observed in static loading, the shear strength of saturated concrete is about twice reduced compared to the dry one.

Figure 9 displays a photo of a wet high-strength concrete specimen after dynamic test. Under naked eye observation, failure patterns are very similar to those seen after static test, that is several horizontal cracks characterized by the fracture of aggregates.

\section{Comparison with the Behavior of the Ordinary Concrete}

Figure 10 plots the curves obtained from dynamic quasioedometric compression tests performed on dry samples of the high-strength concrete and the ordinary concrete. The results are similar to that of static tests. Volumetric strain

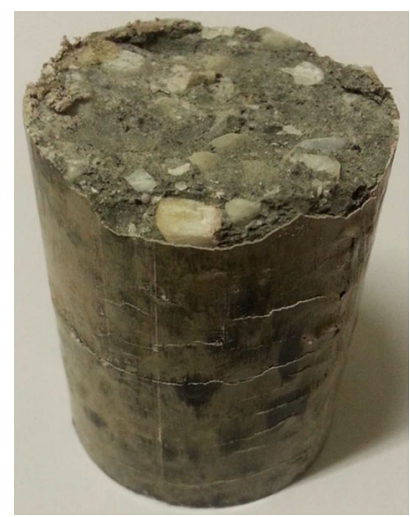

Fig. 9 Image of a wet high-strength concrete specimen tested in dynamic quasi-oedometric compression

of the high-strain concrete is lower than that of the ordinary concrete. On the other hand, both concretes reach the same level of the deviatoric stress. 


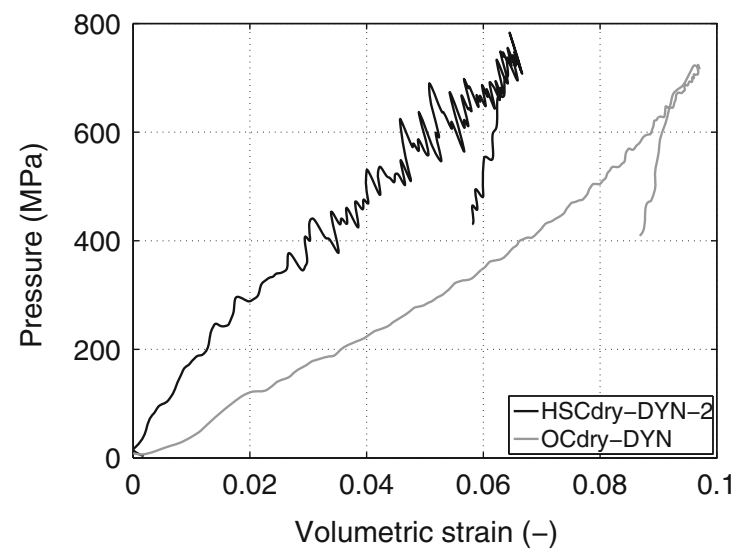

(a)

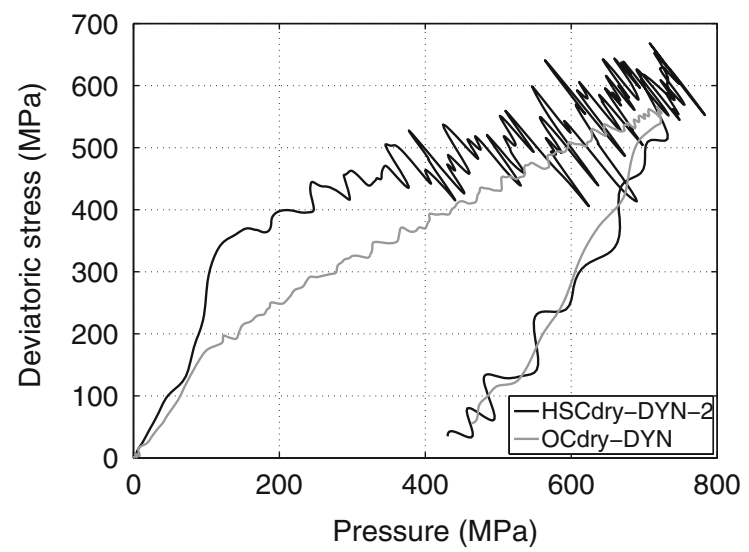

(b)

Fig. 10 Comparison of the behaviors of high-strength concrete HSC and ordinary concrete OC under dynamic quasi-oedometric compression: dry specimens

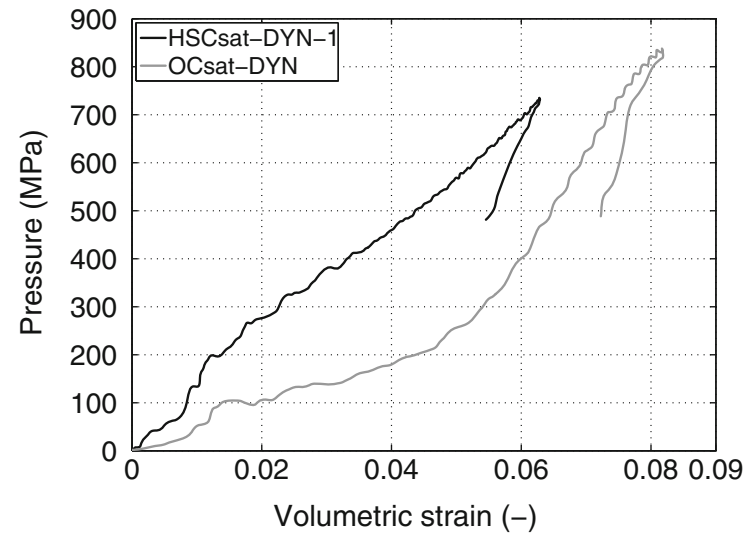

(a)

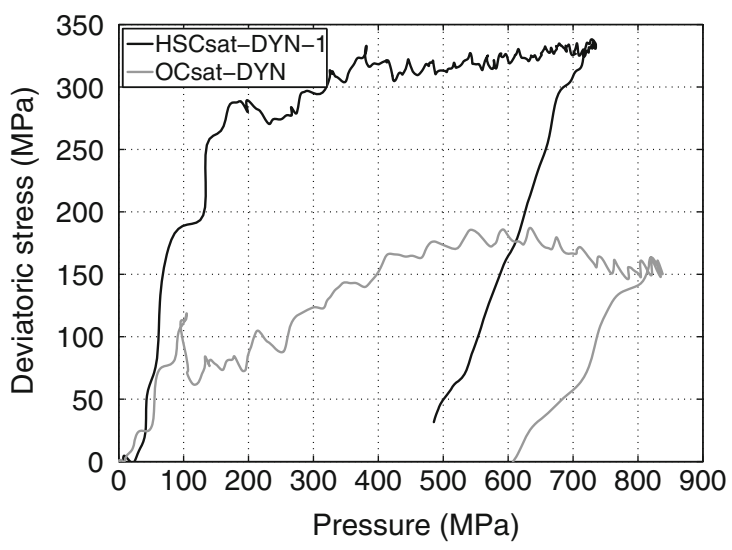

(b)

Fig. 11 Comparison of the behaviors of high-strength concrete HSC and ordinary concrete OC under dynamic quasi-oedometric compression: saturated specimens

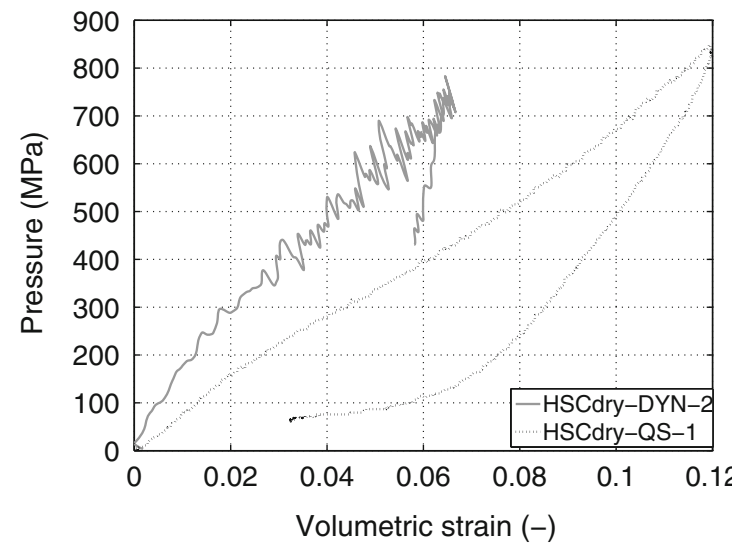

(a)

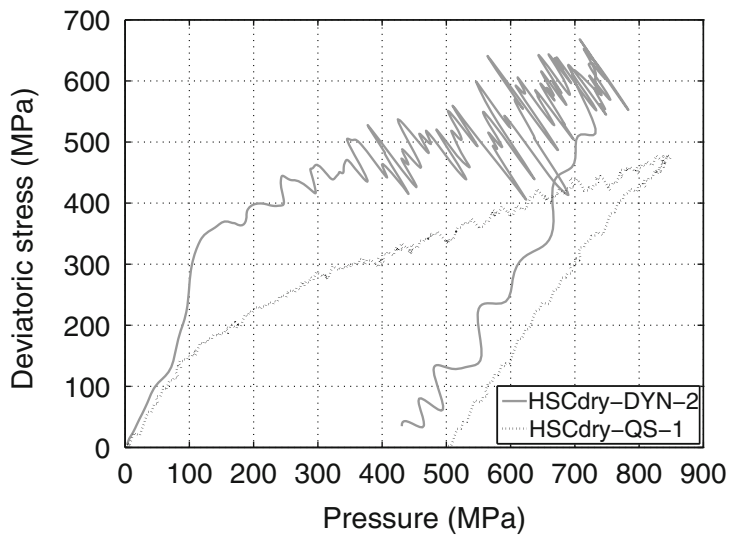

(b)

Fig. 12 Comparison of the behavior of high-strength concrete under static and dynamic quasi-oedometric compression: dry specimens 


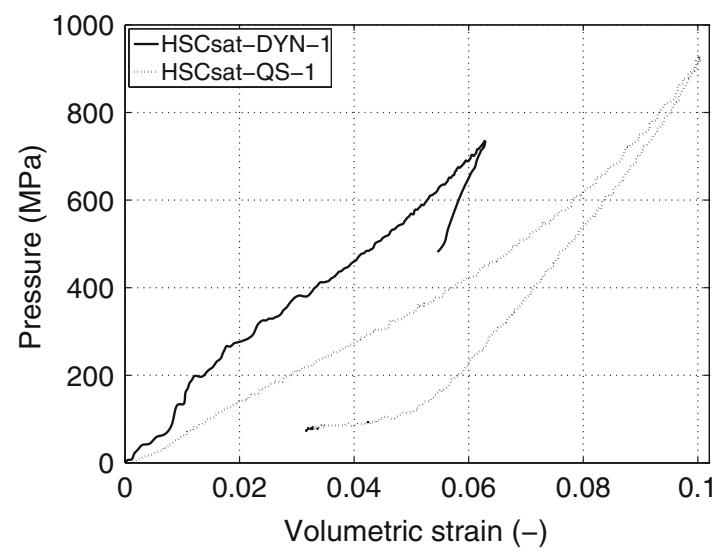

(a)

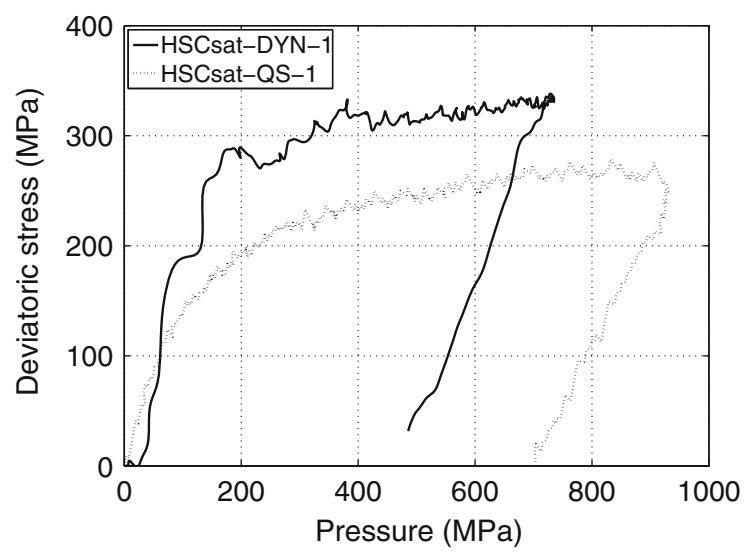

(b)

Fig. 13 Comparison of the behavior of high-strength concrete under static and dynamic quasi-oedometric compression: saturated specimens

Figure 11 compares the behaviors of the two concretes in the saturated state. As in static conditions, supposedly due to its lower porosity, high-strength concrete shows a stiffer volumetric behavior than ordinary concrete. As it was observed in static tests, deviatoric strength of the wet high-strength concrete is much higher than that of ordinary concrete. The relative behavior of the two concretes appears to be more dependent on the free water content rather than on the loading velocity.

\section{Discussion: Influence of the Strain Rate on the Behavior of High-Strength Concrete}

The new results concerning the behavior of the highstrength concrete at very high confinement were presented in this article. Both dried and saturated samples were tested under quasi-oedometric compression in static and dynamic loading. In order to evaluate how the uniaxial compressive strength and the initial porosity of concrete affects its behavior at high confinement, the behavior of the highstrength concrete was compared with the behavior of the ordinary concrete. It was observed that under both static and dynamic quasi-oedometric compression, dry specimens of the two concretes reach similar levels of the shear strength. However, when concrete specimens are saturated, the deviatoric strength of the high-strength concrete strongly exceeds that of the ordinary concrete.

Figures 12 and 13 illustrate the influence of the loading rate on the behavior of the high-strength concrete, respectively in dry and saturated states. The present experimental study demonstrates a strong influence of the strain rate and the free water content on both volumetric and deviatoric behaviors of high-strength concrete. The major results clearly show that dynamic loading increases both volumetric stiffness and deviatoric strength of concrete, whenever it is dry or wet. Moreover, the increase of concrete strength with the strain rate is dependent on the free water content, and is more pronounced for dry specimens.

Acknowledgments The GIGA press has been installed in the 3SR Laboratory within the scope of a cooperative agreement with the CEA-Gramat (France). This research has been performed with the financial support of the Gramat Research Center (CEA-Gramat). Dynamic tests were conducted in the LMS laboratory (Palaiseau, France). We would like to thank Prof. Gérard Gary and Philippe Chevallier (LMS, Palaiseau) for their sound scientific and technical advice, and Prof. Patrick Le Tallec, director of the LMS, for the warm welcome.

\section{References}

1. Aïtcin PC (1983) Condensed silica fume. Université de Sherbrooke

2. Bacon C, Carlsson J, Lataillade J (1991) Evaluation of force and particle velocity at the heated end of a rod subjected to impact loading. Le Journal de Physique IV 1(C3):C3-395

3. Bazant Z, Bishop F, Chang T (1986) Confined compression tests of cement paste and concrete up to $300 \mathrm{ksi}$. ACI J Proc 83:553-560

4. Burlion N, Pijaudier-Cabot G, Dahan N (2001) Experimental analysis of compaction of concrete and mortar. Int J Numer Anal Methods Geomech 25(15):1467-1486

5. Forquin P, Arias A, Zaera R (2007) An experimental method of measuring the confined compression strength of geomaterials. Int J Solids Struct 44(13):4291-4317

6. Forquin P, Arias A, Zaera R (2008) Role of porosity in controlling the mechanical and impact behaviours of cement-based materials. Int J Impact Eng 35(3):133-146

7. Forquin P, Gary G, Gatuingt F (2008) A testing technique for concrete under confinement at high rates of strain. Int $\mathrm{J}$ Impact Eng 35(6):425-446

8. Forquin P, Safa K, Gary G (2010) Influence of free water on the quasi-static and dynamic strength of concrete in confined compression tests. Cem Concr Res 40(2):321-333

9. Frew D, Forrestal MJ, Chen W (2002) Pulse shaping techniques for testing brittle materials with a split hopkinson pressure bar. Exp Mech 42(1):93-106 
10. Gabet T, Malecot Y, Daudeville L (2008) Triaxial behaviour of concrete under high stresses: influence of the loading path on compaction and limit states. Cem Concr Res 38(3):403-412

11. Gary G (2005) DAVID, user's manual, Palaiseau, France. www. lms.polytechnique.fr/EQUIPE/dynamique/index.html

12. Heard W, Martin B, Nie X, Slawson T, Basu P (2014) Annular pulse shaping technique for large-diameter kolsky bar experiments on concrete. Exp Mech 54(8):1343-1354

13. Kolsky H (1949) An investigation of the mechanical properties of materials at very high rates of loading. Proc Phys Soc Sect B 62(11):676

14. Nemat-Nasser S, Isaacs JB, Starrett JE (1991) Hopkinson techniques for dynamic recovery experiments. Proc R Soc Lond Ser A 435(1894):371-391

15. Piotrowska E, Malecot Y, Ke Y (2014) Experimental investigation of the effect of coarse aggregate shape and composition on concrete triaxial behavior. Mech Mater 79:45-57

16. Poinard C, Malecot Y, Daudeville L (2010) Damage of concrete in a very high stress state: experimental investigation. Mater Struct 43:15-29

17. Schmidt M, Cazacu O, Green M (2009) Experimental and theoretical investigation of the high-pressure behavior of concrete. Int J Numer Anal Methods Geomech 33(1):1-23

18. Sfer D, Carol I, Gettu R, Etse G (2002) Study of the behavior of concrete under triaxial compression. J Eng Mech 128(2):156-163
19. Vu X, Daudeville L, Malecot Y (2011) Effect of coarse aggregate size and cement paste volume on concrete behavior under high triaxial compression loading. Constr Build Mater 25(10):39413949

20. Vu X, Malecot Y, Daudeville L, Buzaud E (2009) Effect of the water/cement ratio on concrete behavior under extreme loading. Int J Numer Anal Methods Geomech 33(17):1867-1888

21. Vu X, Malecot Y, Daudeville L, Buzaud E (2009) Experimental analysis of concrete behavior under high confinement: Effect of the saturation ratio. Int J Solids Struct 46(5):1105-1120

22. Warren T, Fossum A, Frew D (2004) Experimental investigation of size effect in concrete fracture under multiaxial compression into low-strength (23 mpa) concrete: target characterization and simulations. Int J Impact Eng 30:477-503

23. Zhao H, Gary G (1996) On the use of shpb techniques to determine the dynamic behavior of materials in the range of small strains. Int J Solids Struct 33(23):3363-3375

24. Zingg L (2013) Influence de la porosité et du degré d'humidité interne sur le comportement triaxial du béton. Ph.D. thesis, Université de Grenoble, France

25. Zukas J (1992) Penetration and perforation of solids. Impact dynamics. Krieger Publishing Co, New York 